\title{
Qol-Resistance Stability in Relation to Pathogenic and Saprophytic Fitness Components of Alternaria alternata from Citrus
}

\author{
Byron Vega and Megan M. Dewdney, Citrus Research and Education Center, University of Florida, Lake Alfred
}

\begin{abstract}
Vega, B., and Dewdney, M. M. 2014. QoI-resistance stability in relation to pathogenic and saprophytic fitness components of Alternaria alternata from citrus. Plant Dis. 98:1371-1378.

The phenotypic stability, fitness components, and ability to cause disease of isolates of the Alternaria alternata tangerine pathotype resistant to quinone-outside inhibitors (QoIs) were studied. Stability of resistance to azoxystrobin (AZ) and pyraclostrobin (PYR) was determined after consecutive transfers on potato dextrose agar (PDA). The sensitivity to QoIs did not change significantly after 10 transfers on PDA compared with the initial sensitivity of all isolates tested. Fitness components evaluated in vitro were mycelial growth, conidial germination, and conidial production. Incubation period, number of lesions per leaf area, and virulence were determined with detached leaf assays using four cultivars: Dancy, Minneola, Murcott, and Sunburst. Variability in fitness components was observed among isolates within

mean values of these fitness components were observed between resistant and sensitive phenotypes, except for virulence. Resistant isolates were significantly $(P<0.05)$ more virulent than the sensitive isolates on Dancy, Minneola, and Sunburst but not on Murcott $(P=$ 0.3506). There was no significant correlation between individual fitness components and the level of sensitivity to AZ and PYR. Preventive applications of Abound (commercial formulation of AZ) at full field rates failed to control disease caused by QoI-resistant isolates under greenhouse conditions. Our results suggest that QoI resistance in A. alternata tangerine pathotype is stable in the absence of QoI selection pressure and that resistance development did not affect the fitness of resistant isolates.
\end{abstract} the same sensitivity group. As a group, no significant differences in the
Fungicide resistance is a serious problem for disease management programs, especially if there is intensive use of site-specific fungicides. The development, stability, and evolution of resistance in fungal populations are dependent on the parasitic and pathogenic fitness of the resistant members of the population $(6,13)$. Fitness is defined as the survival and reproductive success of an allele, individual, or group (47). The use of fungicides on a plant pathogen population can generate a selective pressure for resistant isolates in a fungicide-treated environment if there is an appropriate level of resistance variation in the population (43). Under this scenario, resistant isolates will be selected and the population frequency will increase in subsequent generations, leading to fungicide control failure over time. Cases of field resistance, especially to quinone outside inhibitors (QoIs), have been widely documented (19) since the first report in Blumeria graminis f. sp. tritici in Germany after 2 years of QoI use, suggesting that resistance and stability were not associated with fitness cost (7).

Even though most of the mathematical models used in theoretical studies of fungicide resistance assume a fitness cost associated with resistance (54), fitness penalties in resistant isolates seem to be dependent on the pathogen and, possibly, on the mode of action of the fungicide. For example, MBC-resistant isolates are as fit as sensitive isolates in many fungal species $(11,46,50)$. Similarly, mefenoxam-resistant isolates of Phytophthora erythroseptica (10) and anilinopyrimidine-resistant isolates of Botrytis cinerea did not differ in aggressiveness from sensitive isolates (6). In contrast, the sclerotia of dicarboximide-resistant isolates of $B$. cinerea were less viable and had less sporulation than sensitive isolates (48). Also, dicarboximide-resistant isolates of Monilinia fructicola produced smaller lesions and sporulated less on peach fruit than sensitive isolates (49). In some studies, fitness components were evaluated

Corresponding author: M. M. Dewdney, E-mail: mmdewdney@ufl.edu

Accepted for publication 13 April 2014.

http://dx.doi.org/10.1094/PDIS-01-14-0078-RE

(C) 2014 The American Phytopathological Society with resistant isolates generated in the laboratory to assess the risk for fungicide resistance (8). Although fitness parameters of laboratory-generated mutants can be used to estimate fungicide resistance, it is unknown whether laboratory-induced resistant mutants are representative of those found in the field. Furthermore, laboratory-resistant mutants could incorporate several mutations, produced by the mutagenesis process, which could potentially mask the real impact of the target mutant allele (8). Therefore, the study of fitness of fungicide-resistant isolates should be done using field-resistant isolates when possible.

Resistance stability is also an important element for estimation and prediction of resistance risks. Therefore, it has been studied in multiple pathogens under different selection pressure environments. Resistance stability could be defined as the ability of the pathogen to retain the same level of fungicide insensitivity after successive generations of either exposure or no exposure to the target fungicide (8). Instability of resistance to demethylation inhibitor (DMI) fungicides has been reported in Cercospora beticola (25), Venturia inaequalis (30), and M. fruticola (13). It was shown that some environmental factors, such as cold, may exacerbate the instability $(13,25,30)$. In those cases, the frequency and the levels of change in DMI sensitivity were commonly observed in isolates with moderate to high levels of resistance (30). For QoI fungicides, resistance stability has been detected in some field and laboratory mutants after many consecutive propagations $(5,12,26,31)$. However, a reduction in QoI resistance, or a complete loss of resistance, also has been detected in field and laboratory mutants $(22,32,34,58,59)$. Because generalizations about QoI resistance stability cannot be made, it should be evaluated individually for each fungus using field-resistant isolates.

Within Alternaria alternata, seven different pathotypes have been identified to produce host-selective or host-specific toxins (HSTs) (52). The HSTs are secondary metabolites that cause damage only to the susceptible host (52), and are released during conidium germination, before tissue penetration and mycelium production (38). A. alternata (Fr.) Keissl. causes Alternaria brown spot (ABS) of tangerine (Citrus reticulata Blanco) and its hybrids, which is the most important foliar fungal disease of tangerine in Florida. ABS management has been largely dependent on the use 
of fungicides, especially the QoIs. Due to the specific mode of action of QoIs (blocking electron transport by binding to the Qo site of the mitochondrial cytochrome $b c_{1}$ complex), the risk for development of resistance is high (7). A target site mutation of the cytochrome $b$ gene, resulting in a specific amino acid substitution, prevents fungicide binding at the target site, leading to QoI resistance (7). Three amino acid substitutions in the cytochrome $b$ protein have been detected in QoI-resistant plant-pathogenic fungi and oomycetes (16). The amino acid substitution from glycine to alanine at position 143 (G143A) has been reported in most of the resistant pathogens, leading to a high resistance factor $(>100)$. This mutation has been associated with QoI-control failures (18). Two other mutations, F129L and G137R, are occasionally found in some fungi but have lower resistance factors, and pathogen populations are usually controlled with recommended field rates of QoI fungicides (16). Multiple cases of QoI resistance, including $A$. alternata from tangerine, have been reported (19). A high frequency of QoI-resistant isolates, carrying the G143A mutation, was found in the most important tangerine-producing counties in Florida (56), suggesting that QoI resistance in A. alternata populations may not be associated with a fitness cost.

Currently, little is known about the fitness components and stability of QoI resistance in the tangerine pathotype of A. alternata. Because QoIs are still important tools for ABS management, the stability and fitness of QoI-resistant isolates merit investigation. The specific aims of this study were to (i) determine in vitro stability of field QoI-resistant isolates of A. alternata, (ii) assess whether saprophytic and parasitic fitness costs are associated with QoI resistance in A. alternata isolates, and (iii) evaluate the ability of $A$. alternata QoI-resistant isolates to cause disease on fungicidetreated plants.

\section{Materials and Methods}

Fungal isolates. In all, 10 QoI-resistant and 10 QoI-sensitive single-conidium-derived isolates of A. alternata were used in this study (Table 1). The isolates were collected from tangerine and tangerine hybrid orchards in Florida for a study conducted from 2008 to 2012 to determine the fungicide sensitivity of A. alternata isolates to azoxystrobin and pyraclostrobin (56). The effective concentrations needed to reduce the fungal growth by $50 \%\left(\mathrm{EC}_{50}\right.$ values) were determined using the resazurin-based microtiter assay, according to a previously described procedure (57). Isolates were maintained for long-term storage on sterile filter paper at $-20^{\circ} \mathrm{C}$, as previously described (40).

DNA extraction and molecular detection of the G143A mutation. Genomic DNA was extracted from 3-day-old mycelia cultured on potato dextrose agar (PDA) overlaid with cellophane sheets following previously described procedures (56). The cytochrome $b$ gene of $A$. alternata isolates was partially amplified using the primers cytb2f (5'-CTA TGG ATC TTA CAG AGC AC-3') and DTRcytb2-INTr (5'-GTA TGT AAC CGT CTC CGT C-3'). PCR amplifications were carried out following procedures and conditions previously described (56). Isolates that amplified a $377-$ bp fragment were designated as profile I, whereas isolates that amplified a 1,564-bp fragment were designated as profile II, based on the presence of one or two introns, respectively $(56,57)$. Polymerase chain reaction (PCR) products were purified and digested with the restriction enzyme Fnu4HI to identify the sequence GCTGC at codon 143 and 144 of the cytochrome $b$ gene only observed in resistant isolates (56). Restriction fragments were separated and visualized by electrophoresis in a $1.6 \%$ agarose gel.

Phenotypic stability of QoI-resistant and -sensitive isolates. To measure the stability of resistance, 10 QoI-resistant and 10 QoIsensitive isolates were subcultured on fungicide-free PDA (Becton Dickinson). Isolates were initially transferred from stock cultures on sterile filter paper to PDA to obtain actively growing cultures. Mycelial plugs from the margin of actively growing colonies were transferred to fresh PDA and incubated for 5 days at $24^{\circ} \mathrm{C}$ to be used as the starting material. Isolates were subcultured every 7 days by transferring a 5-mm mycelial plug onto fresh PDA plates and incubated at the conditions described above for a total of 10 times. The sensitivity to azoxystrobin and pyraclostrobin was tested at the initial and final generation of each isolate, using the resazurin-based microtiter assay (57). Briefly, technical-grade azoxystrobin (Syngenta Crop Protection) and pyraclostrobin (BASF Corp.) were dissolved in acetone at $10 \mathrm{mg} / \mathrm{ml}$ (active ingredient) and serially diluted 10-fold. The final concentrations evaluated of azoxystrobin or pyraclostrobin were $0,0.001,0.01,0.05$, $0.1,0.5,1$ or $10 \mu \mathrm{g} / \mathrm{ml}$ and $0,0.001,0.005,0.01,0.05,0.1,1$, or 10 $\mu \mathrm{g} / \mathrm{ml}$, respectively. Three wells per plate were used for each fungi-

Table 1. Molecular characterization and changes of azoxystrobin and pyraclostrobin sensitivities of Alternaria alternata isolates after 10 consecutive subculture cycles on fungicide-free potato dextrose agar (PDA)

\begin{tabular}{|c|c|c|c|c|c|c|c|c|c|}
\hline \multirow[b]{2}{*}{ Isolate } & \multirow[b]{2}{*}{ Host $^{w}$} & \multirow[b]{2}{*}{ Type $^{\mathrm{x}}$} & \multirow[b]{2}{*}{ cyt $^{\mathbf{y}}$} & \multicolumn{3}{|c|}{$\mathrm{EC}_{50}(\mu \mathrm{g} / \mathrm{ml})$ of azoxystrobin } & \multicolumn{3}{|c|}{$\mathrm{EC}_{50}(\mu \mathrm{g} / \mathrm{ml})$ of pyraclostrobin } \\
\hline & & & & Initial & Final & $P^{\mathrm{z}}$ & Initial & Final & $\boldsymbol{P}$ \\
\hline G6-R3-L1 & Minneola tangelo & $\mathrm{S}$ & I & 0.043 & 0.048 & 0.886 & 0.007 & 0.007 & 0.747 \\
\hline G6-R10-F2 & Murcott tangor & $\mathrm{R}$ & II & $>10$ & $>10$ & $\ldots$ & 2.205 & 2.415 & 0.684 \\
\hline G7-R7-L2-1S & Murcott tangor & $\mathrm{S}$ & $\mathrm{I}$ & 0.025 & 0.029 & 0.567 & 0.012 & 0.011 & 0.471 \\
\hline G10-R7-F4-1S & Sunburst tangerine & $\mathrm{S}$ & I & 0.034 & 0.035 & 0.837 & 0.005 & 0.005 & 0.698 \\
\hline G11-R10-L3 & Dancy mandarin & $\mathrm{R}$ & I & $>10$ & $>10$ & $\ldots$ & 2.029 & 2.779 & 0.616 \\
\hline G14-L11-1S & Murcott tangor & $\mathrm{R}$ & II & $>10$ & $>10$ & $\ldots$ & 4.553 & 4.369 & 0.551 \\
\hline G19-R5-L1 & Minneola tangelo & $\mathrm{R}$ & II & $>10$ & $>10$ & $\ldots$ & 3.414 & 4.097 & 0.717 \\
\hline G22-R28-F1 & Sunburst tangerine & $\mathrm{R}$ & II & $>10$ & $>10$ & $\ldots$ & 3.308 & 3.840 & 0.328 \\
\hline G27-B3T-L2 & Sunburst tangerine & $\mathrm{S}$ & $\mathrm{I}$ & 0.236 & 0.267 & 0.866 & 0.031 & 0.038 & 0.555 \\
\hline G28-R14-L1-1S & Sunburst tangerine & $\mathrm{R}$ & II & $>10$ & $>10$ & $\ldots$ & 6.273 & 6.079 & 0.893 \\
\hline G29-R9-F1-1S & Orlando tangelo & $\mathrm{S}$ & $\mathrm{I}$ & 0.087 & 0.096 & 0.659 & 0.022 & 0.021 & 0.256 \\
\hline G31-R2-L1 & Murcott tangor & $\mathrm{S}$ & I & 0.015 & 0.019 & 0.035 & 0.005 & 0.006 & 0.445 \\
\hline G34-R4-F5 & Minneola tangelo & $\mathrm{R}$ & II & $>10$ & $>10$ & $\ldots$ & 2.049 & 2.277 & 0.861 \\
\hline G37-R5-L1-1S & Orlando tangelo & $\mathrm{S}$ & $\mathrm{I}$ & 0.100 & 0.082 & 0.484 & 0.041 & 0.038 & 0.729 \\
\hline G39-R9-L2-1S & Orlando tangelo & $\mathrm{R}$ & I & $>10$ & $>10$ & $\ldots$ & 3.612 & 3.744 & 0.630 \\
\hline G40-F5-1S & Dancy mandarin & $\mathrm{R}$ & $\mathrm{I}$ & $>10$ & $>10$ & $\ldots$ & 5.488 & 5.459 & 0.946 \\
\hline G40-R7-F2 & Dancy mandarin & $\mathrm{S}$ & I & 0.076 & 0.097 & 0.027 & 0.012 & 0.012 & 0.942 \\
\hline G42-R6-3-L2 & Minneola tangelo & $\mathrm{S}$ & I & 0.097 & 0.117 & 0.736 & 0.010 & 0.010 & 0.745 \\
\hline G45-R12-L1-1S & Lee citrus hybrid & $\mathrm{R}$ & $\mathrm{I}$ & $>10$ & $>10$ & $\ldots$ & 4.603 & 4.249 & 0.523 \\
\hline G45-R13-F1-1S & Lee citrus hybrid & $\mathrm{S}$ & I & 0.038 & 0.034 & 0.755 & 0.019 & 0.017 & 0.511 \\
\hline
\end{tabular}

${ }^{\mathrm{w}}$ Tangelo $=$ Citrus paradisi $\times C$. reticulata, tangor $=C$. reticulata $\times C$. sinensis, tangerine or mandarin $=C$. reticulata, and citrus hybrid $=C$. reticulata $\times$ tangelo.

${ }^{x} \mathrm{~S}=$ sensitive and $\mathrm{R}=$ resistant.

${ }^{y}$ Gene profile; $c y t b$ profile I contains one intron (amino acid position F164), and $c y t b$ profile II contains two introns (amino acid positions A126 and F164).

${ }^{z}$ The two sample $t$ test was performed to determine whether the differences in sensitivity between the initial generation and the 10th transfer in PDA were significant $(\alpha=0.05)$. 
cide concentration. The $\mathrm{EC}_{50}$ values for azoxystrobin and pyraclostrobin were calculated using either sigmoidal or exponential decay functions by plotting the percent resazurin reduction relative to the control against the $\log _{10}$-transformed fungicide concentration with SigmaPlot (ver. 11.0; Systat Software Inc.).

The experiment was performed twice as a factorial arrangement in a completely randomized design (CRD) with five isolate-replications. $\mathrm{EC}_{50}$ values were $\log _{10}$-transformed prior to testing for normality using the Shapiro-Wilk test in PROC UNIVARIATE (ver. 9.3; SAS Institute) and graphically analyzed. The homogeneity of variance was analyzed using the ratio of variance of two independent experiments prior to pooling the experiments. Data were analyzed by three-way analysis of variance (ANOVA) with sensitivity groups (QoI-resistant and -sensitive), fungicides (azoxystrobin and pyraclostrobin), and time points (before and after subculturing) as factors, using PROC GLM (SAS Institute). A two-sample Student's $t$ test was performed using PROC TTEST (SAS Institute) to determine differences between the initial and final $\mathrm{EC}_{50}$ values of each isolate.

Saprophytic fitness components. The following fitness components were evaluated in vitro for 10 QoI-resistant and 10 QoIsensitive A. alternata isolates: (i) mycelial growth on PDA, (ii) conidial production on V-8 agar, and (iii) germination on water agar. All the experiments were performed twice.

Mycelial growth. Isolates were retrieved from stock cultures as mentioned above. After 5 days of growth, mycelial plugs $(5 \mathrm{~mm}$ in diameter) were transferred from the margin of actively growing cultures to the center of fresh PDA plates. The plates were incubated at $24^{\circ} \mathrm{C}$ for 7 days in the dark and then the colony diameters were measured at two perpendicular points. For each isolate, four replicate plates were used.

Conidial production. Mycelial plugs were transferred from 5day-old PDA cultures to the center of clarified V8 agar (100 $\mathrm{ml}$ of centrifuged V8 juice, $20 \mathrm{~g}$ of agar and $10 \mathrm{~g}$ of $\mathrm{CaCO}_{3}$ per liter) plates. Plates were incubated for 7 days at room temperature (approximately $22^{\circ} \mathrm{C}$ ) under cool white fluorescent light. Conidia were harvested by flooding each plate with $15 \mathrm{ml}$ of sterile deionized water, gently rubbing the surface, and filtering through three layers of sterile cheesecloth. Conidial concentration was estimated with a hemacytometer and expressed as the number of conidia per square millimeter of the colonized medium. Four replicate plates were used for each isolate, and four droplets $(10 \mu \mathrm{l})$ of the conidial suspension were counted per plate.

Conidial germination. After the measurement of conidial production, a $10-\mu l$ aliquot of the conidial suspension $\left(1 \times 10^{5}\right.$ conidia/ml) was deposited onto the surface of $2 \%$ water agar-coated glass slides, placed into individual petri dishes with moistened filter paper, and incubated at $24^{\circ} \mathrm{C}$ for $18 \mathrm{~h}$. Germination was quantified by counting 100 conidia per slide on four replicate slides per isolate. A conidium was considered germinated if the germ tube was at least the length of the conidium, if an appressorium was present, or if multiple germ tubes were observed.

The experiments were arranged in a CRD with four replications. Data from two independent experiments were pooled after testing for homogeneity of variance, as described above. Percentage data were arcsine square root transformed prior to analysis. One-way ANOVA was performed using PROC GLM (SAS Institute) to determine statistical differences in fitness parameters between resistant and sensitive isolates. Data from conidial production were analyzed by subsampling one-way ANOVA, using PROC MIXED (SAS Institute). Mean values of each isolate-within-phenotype group were separated using Tukey's significance test $(\alpha=0.05)$.

Pathogenic fitness components. Incubation period (the time from inoculation to initial symptom appearance), the number of lesions per square centimeter of leaf, and the virulence of five QoIsensitive and five QoI-resistant isolates were evaluated by inoculating disease-free immature leaves of 'Minneola' tangelo, 'Dancy' mandarin, 'Murcott' tangor, and 'Sunburst' tangerine using an in vitro detached leaf assay. Leaves for inoculation were from 8- to 10 -year-old trees, grown in soilless potting mix (24-liter pots) in the screenhouse. Prior to use, plants were pruned to induce a uniform growth flush. Young leaves, about $3 \mathrm{~cm}$ long, were collected for inoculation. For each fungal isolate, 10 replicate leaves of each cultivar were sprayed with $2 \times 10^{4}$ conidia/ml using a chromatography sprayer (TLC Crown North American Professional Products), as previously described (9). Inoculated leaves were placed in racks inside a clean humid chamber and incubated at room temperature (approximately $22^{\circ} \mathrm{C}$ ). Leaves were monitored every hour (after the first $12 \mathrm{~h}$ postinoculation) for the appearance of brown spot symptoms. Mean incubation period for each isolate was calculated based on observations of 10 leaves per cultivar. Two days after inoculation, the number of lesions per leaf was counted and isolate virulence was determined by rating the leaf area covered by lesions on a scale of 1 to 3 , where $1=<25 \%$ leaf area diseased, $2=$ between 25 and 50\% leaf area diseased, and $3=>50 \%$ leaf area diseased. Leaf area was assessed by scanning individual leaves in a JPEG file format using a flatbed scanner at 7,000 by 5,100 dpi (Epson). The image was converted into binary form via eight-bit gray scale image before analysis. JPEG image files were loaded into the ImageJ platform (United States National Institute of Health, http://rsbweb.nih.gov/ij) for digital image analysis to determine the leaf area. Data were expressed as the number of lesions per square centimeter of leaf.

The experiment was performed twice as a factorial, arranged in a CRD with 10 replications, with cultivars and sensitivity groups as factors. Data from two independent experiments were pooled after testing for homogeneity of variance, as described above. Mean values of each isolate-within-phenotype group were separated using Tukey's significance test $(\alpha=0.05)$. The nonparametric Kruskal-Wallis $H$ test was performed to determine differences in virulence between resistant and sensitive isolates, using PROC NPAR1WAY (SAS Institute). Correlation coefficients between mean fitness components and the $\mathrm{EC}_{50} \log _{10}$-transformed values were estimated by calculating a Pearson correlation coefficient using PROC REG and PROC CORR (SAS Institute). Isolates with $\mathrm{EC}_{50}$ values higher than $10 \mu \mathrm{g} / \mathrm{ml}$ were not included in the correlation and regression analyses.

Efficacy of azoxystrobin for control of ABS caused by QoIsensitive and -resistant isolates. Potted 2-year-old 'Murcott' tangor grafted on 'Sun Chu Sha' rootstock were used to evaluate the protective activity of azoxystrobin for ABS control using five QoI-sensitive and five QoI-resistant isolates. Plants were grown in 3.4-liter containers in the greenhouse to a height of 0.75 to $1.0 \mathrm{~m}$. Prior to the initiation of the experiments, plants were pruned to produce new flush of uniform size and age. One day prior to inoculation (3 to 6 weeks after pruning), azoxystrobin as Abound (Syngenta Crop Protection) or water as a control were applied. Abound was applied at the maximum-label rate recommended by the manufacturer for ABS control (242 mg a.i./liter). Plants were sprayed to run-off using a hand-pump sprayer. Three single-plant replications were used for each treatment. The experiment was performed twice.

One day after fungicide or water applications, plants were individually inoculated with a conidial suspension $\left(1 \times 10^{5}\right.$ conidia/ml $)$ of five selected QoI-resistant or five QoI-sensitive isolates, one isolate per plant. Inoculum was produced as described above. Inoculations were conducted by spraying the new flush to run-off with conidial suspensions using a chromatography sprayer (TLC Crown). Plants were covered with premoistened plastic bags and placed in a mist bed in the greenhouse at ambient temperature (20 to $30^{\circ} \mathrm{C}$ ) and light conditions. The bags were misted for $20 \mathrm{~s}$ every $5 \mathrm{~min}$ to keep the plants and bags moist for 16 to $20 \mathrm{~h}$; then, the plants were placed on greenhouse benches, with no mist, for symptom development. Five days after inoculation, the number of lesions per leaf was counted on 20 leaves of each replicate plant and the mean number of lesions per leaf was calculated for each isolate.

The effect of azoxystrobin on ABS was assessed using a factorial treatment arrangement in a CRD with three single-plant replications for each treatment. Data from two independent experiments 
were pooled after testing for homogeneity of variance, as described above. The number of lesions per leaf was square root transformed prior to analysis. Data were analyzed by two-way ANOVA with sensitivity groups (QoI-resistant and -sensitive) and products (azoxystrobin and water) as factors, using PROC GLM (SAS Institute).

\section{Results}

QoI sensitivity and detection of the G143A mutation. The mean $\mathrm{EC}_{50}$ value of 10 QoI-sensitive isolates for azoxystrobin and pyraclostrobin was significantly different $(t=37.77, P<0.0001$ and $t=42.04, P<0.0001$, respectively) from the mean $\mathrm{EC}_{50}$ value of 10 QoI-resistant isolates. Isolates were more sensitive to pyraclostrobin than azoxystrobin $(P<0.0001)$, as previously reported (56). The $\mathrm{EC}_{50}$ values for sensitive isolates were 0.015 to 0.236 $\mu \mathrm{g} / \mathrm{ml}$ for azoxystrobin and 0.005 to $0.041 \mu \mathrm{g} / \mathrm{ml}$ for pyraclostrobin (Table 1). Resistant isolates had $\mathrm{EC}_{50}$ values higher than $10 \mu \mathrm{g} / \mathrm{ml}$ for azoxystrobin, whereas $\mathrm{EC}_{50}$ values of the same group of isolates for pyraclostrobin were 2.0 to $6.3 \mu \mathrm{g} / \mathrm{ml}$ (Table 1 ).

Using the PCR restriction fragment length polymorphism, the point mutation of glycine (GGT) to alanine (GCT) at amino acid 143 (G143A) was identified exclusively in resistant isolates. Between sensitive and resistant isolates, the proportion of isolates carrying the cytochrome $b$ profiles I or II was significantly different $\left(\chi^{2}=8.5714, P=0.0034\right)$, as previously reported (56). All sensitive isolates belonged to cytochrome $b$ profile I, whereas four and six resistant isolates belonged to cytochrome $b$ profile I and profile II, respectively (Table 1).

Stability of resistance. Isolates of both QoI-sensitive and -resistant phenotypes maintained their initial azoxystrobin and pyraclostrobin sensitivity levels after 10 consecutive transfers on PDA, with few exceptions (Table 1). Isolates G31-R2-L1 and G40$\mathrm{R} 7-\mathrm{F} 2$ showed a slight increase in the $\mathrm{EC}_{50}$ value of azoxystrobin after 10 consecutive transfers on artificial media. Despite the marginal decrease in azoxystrobin sensitivity, these two isolates

Table 2. Saprophytic fitness components of quinone-outside inhibitorsensitive and -resistant isolates of Alternaria alternata $^{\mathrm{z}}$

\begin{tabular}{llll}
\hline & \multicolumn{3}{c}{ In vitro fitness components } \\
\cline { 2 - 4 } Isolate & $\begin{array}{c}\text { Mycelial } \\
\text { growth } \\
(\mathbf{m m})\end{array}$ & $\begin{array}{c}\text { Conidial } \\
\text { production } \\
\left(\times \mathbf{1 0}^{3} / \mathbf{m m}^{2}\right)\end{array}$ & $\begin{array}{c}\text { Conidial } \\
\text { germination } \\
(\mathbf{\%})\end{array}$ \\
\hline Sensitive & & & \\
G6-R3-L1 & $44.9 \mathrm{ef}$ & $1.45 \mathrm{efgh}$ & $91.3 \mathrm{abcdefg}$ \\
G7-R7-L2-1S & $48.7 \mathrm{de}$ & $3.19 \mathrm{abcd}$ & $95.4 \mathrm{abc}$ \\
G10-R7-F4-1S & $38.1 \mathrm{~g}$ & $0.05 \mathrm{~h}$ & $93.8 \mathrm{abcd}$ \\
G27-B3T-L2 & $41.9 \mathrm{fg}$ & $2.80 \mathrm{abcde}$ & $88.8 \mathrm{cdefg}$ \\
G29-R9-F1-1S & $29.9 \mathrm{~h}$ & $1.44 \mathrm{efgh}$ & $95.9 \mathrm{abc}$ \\
G31-R2-L1 & $69.4 \mathrm{a}$ & $3.39 \mathrm{abc}$ & $76.3 \mathrm{gh}$ \\
G37-R5-L1-1S & $54.6 \mathrm{~cd}$ & $2.55 \mathrm{abcdef}$ & $96.1 \mathrm{abc}$ \\
G40-R7-F2 & $51.1 \mathrm{de}$ & $4.03 \mathrm{a}$ & $62.6 \mathrm{~h}$ \\
G42-R6-3-L2 & $62.1 \mathrm{~b}$ & $1.09 \mathrm{fgh}$ & $92.8 \mathrm{abcdef}$ \\
G45-R13-F1-1S & $36.8 \mathrm{~g}$ & $1.26 \mathrm{fgh}$ & $96.5 \mathrm{abcd}$ \\
Mean & $47.7 \mathrm{~A}$ & $2.12 \mathrm{~A}$ & $82.4 \mathrm{~A}$ \\
Resistant & & & \\
G6-R10-F2 & $47.8 \mathrm{ef}$ & $2.00 \mathrm{cdefg}$ & $89.0 \mathrm{cdefg}$ \\
G11-R10-L3 & $60.9 \mathrm{bc}$ & $3.23 \mathrm{abcd}$ & $85.4 \mathrm{defg}$ \\
G14-L11-1S & $50.1 \mathrm{de}$ & $2.01 \mathrm{cdefg}$ & $97.4 \mathrm{abc}$ \\
G19-R5-L1 & $49.6 \mathrm{de}$ & $2.08 \mathrm{bcdefg}$ & $83.0 \mathrm{fgh}$ \\
G22-R28-F1 & $59.1 \mathrm{bc}$ & $0.95 \mathrm{gh}$ & $90.6 \mathrm{bcdefg}$ \\
G28-R14-L1-1S & $29.9 \mathrm{~h}$ & $2.36 \mathrm{bcdefg}$ & $95.0 \mathrm{abcde}$ \\
G34-R4-F5 & $46.7 \mathrm{ef}$ & $1.76 \mathrm{defg}$ & $83.9 \mathrm{efg}$ \\
G39-R9-L2-1S & $47.4 \mathrm{ef}$ & $3.60 \mathrm{ab}$ & $98.6 \mathrm{a}$ \\
G40-F5-1S & $47.2 \mathrm{ef}$ & $1.84 \mathrm{defg}$ & $93.4 \mathrm{abcdef}$ \\
G45-R12-L1-1S & $48.4 \mathrm{def}$ & $2.34 \mathrm{bcdefg}$ & $98.2 \mathrm{ab}$ \\
Mean & $48.8 \mathrm{~A}$ & $2.22 \mathrm{~A}$ & $86.4 \mathrm{~A}$ \\
\hline 2 & &
\end{tabular}

${ }^{z}$ Means of individual isolates designated by the same lowercase letter within groups are not significantly different according to Tukey's test $(\alpha=$ 0.05). Mean values of groups within columns designated by the same uppercase letter are not significantly different according to Student's $t$ test $(\alpha=0.05)$. remained QoI sensitive. None of the QoI-resistant isolates became sensitive after 10 consecutive transfers on PDA.

Saprophytic fitness. Three saprophytic fitness components were evaluated in vitro for a representative group of QoI-sensitive and -resistant isolates. Great variability among isolates within the same sensitivity group was found in mycelial growth, conidial production, and conidial germination (Table 2).

The mean mycelial growth of both sensitivity groups was not significantly different $(P=0.539)$. In the sensitive group, the mycelial growth was 29.9 to $69.4 \mathrm{~mm}$ with a mean of $47.7 \mathrm{~mm}$ whereas, in the resistant group, the mycelial growth was 29.9 to $60.9 \mathrm{~mm}$ with a mean of $48.8 \mathrm{~mm}$ (Table 2). Similarly, mean conidial production for the sensitive group, which was $2.1 \times 10^{3}$ conidia $/ \mathrm{mm}^{2}$ of medium, was not significantly different $(P=0.418)$ from that of the resistant group, which was $2.2 \times 10^{3}$ conidia $/ \mathrm{mm}^{2}$ of medium (Table 2).

For conidial germination, no significant differences $(P=0.380)$ were detected between the sensitivity groups. In general, isolates showed a conidial germination percentage higher than $80 \%$, with few exceptions (Table 2). Isolate G40-R7-F2 had a significantly lower conidial germination percentage than other isolates.

Pathogenic fitness. Incubation period, disease virulence, and number of lesions per leaf area were evaluated in four citrus cultivars inoculated with five QoI-sensitive and five QoI-resistant isolates. The mean incubation period for 'Minneola' $(15.0 \mathrm{~h})$ and 'Dancy' $(15.2 \mathrm{~h})$ were significantly shorter $(P<0.0001)$ than that for 'Murcott' $(17.4 \mathrm{~h})$ and 'Sunburst' $(16.2 \mathrm{~h})$. No interaction between cultivars and sensitivity groups was found for incubation period $(P=0.728)$.

On the other hand, the interaction between cultivars and sensitivity groups for the number of lesions per square centimeter of leaf was statistically significant $(P=0.036)$. The mean number of lesions per square centimeter of leaf was not significantly different between sensitivity groups for 'Dancy' $(P=0.409)$, 'Minneola' $(P$ $=0.559)$, and 'Murcott' $(P=0.907)$. However, for 'Sunburst', the mean number of lesions per square centimeter of leaf was significantly higher $(P=0.001)$ for resistant isolates (15.6 lesions $/ \mathrm{cm}^{2}$ ) than for sensitive isolates (11.9 lesions $/ \mathrm{cm}^{2}$ ) (Table 3). In general, the number of lesions observed in 'Murcott' was significantly lower $(P<0.0001)$ than in the other cultivars. 'Minneola' and 'Dancy' did not show significant differences between them in the number of lesions, with means of 15.8 and 15.1 lesion $/ \mathrm{cm}^{2}$, respectively $(P=0.332)$.

Virulence was significantly higher $(P<0.05)$ for the resistant group than for the sensitive group in 'Dancy', 'Minneola', and 'Sunburst' but was not significantly different $(P=0.351)$ in Murcott (Table 3 ). Within cultivars, slight variability in virulence among isolates within the same sensitivity group was detected (Table 3 ).

Correlation between fitness and resistance. Correlation coefficients between fitness components and sensitivity to azoxystrobin and pyraclostrobin were estimated. For all fitness components, including mycelial growth (Fig. 1A), conidial production (Fig. 1B), conidial germination (Fig. 1C), incubation time (Fig. 1D), disease severity (Fig. 1E), and number of lesions (Fig. 1F), the correlation coefficients were not significantly different from $0(P>0.05)$, indicating that no relationship existed between the level of sensitivity to azoxystrobin or pyraclostrobin and the respective fitness components.

Efficacy of azoxystrobin in greenhouse experiments. Greenhouse inoculation experiments demonstrated that azoxystrobin (Abound) applied at the highest labeled rate 1 day before inoculation, using five QoI-resistant and five QoI-sensitive isolates, significantly reduced $(P<0.0001)$ the number of lesions produced by sensitive isolates compared with the nonsprayed control (Fig. 2). On the other hand, the number of lesions observed on plants previously exposed to azoxystrobin and inoculated with resistant isolates was not significantly reduced $(P=0.065)$ compared with the unsprayed control (Fig. 2). The efficacy of azoxystrobin in controlling disease caused by those resistant isolates was significantly lower than that caused by sensitive isolates. 


\section{Discussion}

The recent discovery of mixed QoI-resistant and -sensitive isolates in tangerine-infecting A. alternata populations in Florida, as well as the dominance of resistant isolates in many citrus orchards, causing field resistance, increases the concern about the continued use of QoI fungicides in the tangerine industry. It is imperative to implement resistance management strategies in the Florida tangerine industry to delay the selection of QoI-resistant isolates in locations where resistance has not been identified yet, as well as to reduce the proportion of resistance in populations where resistant isolates are present. Information about the biological and ecological fitness components of QoI-resistant isolates, reported in this study, will help provide the basis for the development of such resistance-management strategies.

In our study, the phenotypic stability of QoI-resistant A. alternata isolates was investigated using artificial medium in the absence of QoI selection pressure. After 10 consecutive transfers, none of the resistant isolates had a reduction or loss of resistance, indicating that QoI resistance in the A. alternata tangerine pathotype is stable. This stability suggests that the dominance of QoIresistant populations, observed in the most important tangerineproducing counties in Florida (56), was not a temporary adaptation of the pathogen to the fungicide that could be lost in the absence of selection pressure but, rather, a long-term threat for the tangerine industry. A similar resistance stability was also observed in other pathosystems in field and laboratory mutants of Magnaporthe grisea (5), B. cinerea (26), C. beticola (31), and Erysiphe graminis (12). However, a reduction in the resistance levels or a complete loss of QoI resistance following consecutive transfers using in vitro or in vivo tests has been observed in field isolates of Plasmopara viticola (20), Corynespora cassiicola, Mycovellosiella nattrassii, Colletotrichum gloeosporioides (22), and Mycosphaerella graminicola (34), as well as in laboratory mutants of B. cinerea (32), Ustilago maydis (59), and $V$. inaequalis (58). In some of these cases, resistance instability was attributed to the presence of a heteroplasmic state in the mitochondrial cytochrome $b$, where mitochondria containing both mutant and wild-type alleles reverted to the wildtype cytochrome $b$ at very high frequency, during growth on fungicide-free media $(22,58)$.

Resistance to QoI fungicides associated with the G143A mutation affect the structure of the Qo site and, in turn, might decrease the activity of the cytochrome $b c_{l}$ complex, influencing the fitness of pathogens differentially $(17,18)$. In fact, laboratory mutants of $B$. cinerea and $C$. beticola resistant to QoIs exhibited a significant fitness reduction compared with the wild-type parental isolates $(31,32)$. However, those differences could be attributed to the impact of several mutations in different metabolic pathways produced by the mutagenesis process instead of a pleiotropic effect of the G143A mutation. Our study shows that QoI-resistant A. alternata isolates did not develop any significant vegetative or reproductive fitness penalties, based on the saprophytic fitness components evaluated.

The group of resistant isolates tested in this study showed similar mycelial growth, conidial production, and conidial germination to isolates in the sensitive group. However, within each sensitivity group, great variation was found between isolates for each fitness component studied, suggesting that the variability observed could be attributed to the genetic background of individual isolates within the sensitivity group rather than to a fitness cost, given the fact that there is a great genetic variability among tangerine-infecting A. alternata isolates, as previously reported $(41,45,51)$. Moreover, our results were similar to those reported on field QoI-resistant isolates of B. cinerea from apple (26) and A. alternata from pistachio (24), where no differences in any saprophytic fitness components were found between resistant and sensitive isolates.

Similarly, our results showed that some pathogenic fitness components such as latent period and number of lesions per leaf area did not suffer any fitness penalty from being QoI resistant. Resistant isolates were more aggressive than sensitive isolates on the highly susceptible cultivars such as 'Dancy' and 'Minneola'. However, for the least susceptible cultivar evaluated in this study, 'Murcott' tangor, there was no difference in virulence levels between resistant and sensitive isolates. This could have been caused by the long incubation time and the low rate of disease symptom expansion observed in 'Murcott' but also because 'Murcott' is heterozygous for the locus responsible for ABS susceptibility, whereas 'Minneola' and 'Dancy' are homozygous (14). It is known that cultivars with the homozygous $A B S r$ loci (associated with susceptibility to ABS) are more susceptible to the ACT toxin than are the heterozygotes (52).

Greater disease severity in Alternaria spp. has been found in QoI-resistant isolates carrying both the G143A (24) and the F129L (39) mutations, demonstrating that aggressiveness is independent of the G143A mutation. In the A. alternata tangerine pathotype, the main virulence and pathogenicity factors are dependent on the production of the ACT toxin (27-29). The genes responsible for ACT toxin production are tightly clustered and located on a small chromosome called the conditional dispensable chromosome $(2,21,33)$. Multiple copies of the genes responsible for ACT toxin

Table 3. Pathogenic fitness components of quinone-outside inhibitor-sensitive and -resistant isolates of Alternaria alternata in four citrus cultivars using detached leaves ${ }^{\mathrm{z}}$

\begin{tabular}{|c|c|c|c|c|c|c|c|c|c|c|c|c|}
\hline \multirow[b]{2}{*}{ Isolate } & \multicolumn{3}{|c|}{ Dancy mandarin } & \multicolumn{3}{|c|}{ Minneola tangelo } & \multicolumn{3}{|c|}{ Murcott tangor } & \multicolumn{3}{|c|}{ Sunburst tangerine } \\
\hline & IP & $\mathbf{L}$ & $\mathbf{V}$ & IP & $\mathbf{L}$ & $\mathbf{V}$ & IP & $\mathbf{L}$ & $\mathbf{V}$ & IP & $\mathbf{L}$ & $\mathbf{V}$ \\
\hline \multicolumn{13}{|l|}{ Sensitive } \\
\hline G6-R3-L1 & 15.7 & $10.4 \mathrm{~d}$ & $1.3 \mathrm{~d}$ & 15.1 & $12.1 \mathrm{~b}$ & $1.3 \mathrm{e}$ & $20.0 \mathrm{a}$ & $7.5 \mathrm{c}$ & $1.0 \mathrm{~b}$ & $17.4 \mathrm{a}$ & $7.6 \mathrm{~b}$ & $1.0 \mathrm{c}$ \\
\hline G27-B3T-L2 & 15.2 & $16.5 \mathrm{abc}$ & $1.3 \mathrm{~d}$ & 15.1 & $14.2 \mathrm{ab}$ & $1.6 \mathrm{de}$ & $17.8 \mathrm{ab}$ & $8.9 \mathrm{c}$ & $1.0 \mathrm{~b}$ & $16.8 \mathrm{ab}$ & $10.6 \mathrm{ab}$ & $1.1 \mathrm{bc}$ \\
\hline G31-R2-L1 & 15.3 & $20.3 \mathrm{a}$ & $1.5 \mathrm{~cd}$ & 15.1 & $14.0 \mathrm{ab}$ & 1.7 cde & $18.6 \mathrm{ab}$ & $9.6 \mathrm{c}$ & $1.0 \mathrm{~b}$ & $17.0 \mathrm{ab}$ & $13.1 \mathrm{ab}$ & $1.1 \mathrm{bc}$ \\
\hline G40-R7-F2 & 15.1 & $14.2 \mathrm{bcd}$ & $2.0 \mathrm{ab}$ & 15.0 & $18.5 \mathrm{ab}$ & $1.8 \mathrm{~cd}$ & $15.8 \mathrm{~b}$ & $17.0 \mathrm{a}$ & $1.2 \mathrm{ab}$ & $15.3 \mathrm{~b}$ & $15.4 \mathrm{ab}$ & $1.2 \mathrm{abc}$ \\
\hline G42-R6-3-L2 & 15.0 & $12.6 \mathrm{~cd}$ & $2.0 \mathrm{ab}$ & 15.0 & $18.7 \mathrm{ab}$ & $2.4 \mathrm{ab}$ & $15.6 \mathrm{~b}$ & $16.2 \mathrm{a}$ & $1.3 \mathrm{ab}$ & $15.4 \mathrm{ab}$ & $12.8 \mathrm{ab}$ & $1.2 \mathrm{abc}$ \\
\hline Mean & $15.3 \mathrm{~A}$ & $14.8 \mathrm{~A}$ & $1.6 \mathrm{~B}$ & $15.1 \mathrm{~A}$ & $15.5 \mathrm{~A}$ & $1.7 \mathrm{~B}$ & $17.6 \mathrm{~A}$ & $11.8 \mathrm{~A}$ & $1.1 \mathrm{~A}$ & $16.4 \mathrm{~A}$ & $11.9 \mathrm{~B}$ & $1.1 \mathrm{~B}$ \\
\hline \multicolumn{13}{|l|}{ Resistant } \\
\hline G6-R10-F2 & 15.1 & $18.9 \mathrm{ab}$ & $1.4 \mathrm{~d}$ & 15.1 & $13.6 \mathrm{ab}$ & $1.6 \mathrm{cde}$ & $18.7 \mathrm{ab}$ & $7.9 \mathrm{c}$ & $1.0 \mathrm{~b}$ & $16.3 \mathrm{ab}$ & $17.7 \mathrm{a}$ & $1.2 \mathrm{abc}$ \\
\hline G11-R10-L3 & 15.0 & $14.3 \mathrm{bcd}$ & $2.4 \mathrm{a}$ & 15.0 & $20.2 \mathrm{a}$ & $1.9 \mathrm{bcd}$ & $15.6 \mathrm{~b}$ & $19.3 \mathrm{a}$ & $1.8 \mathrm{a}$ & $15.3 \mathrm{~b}$ & $14.2 \mathrm{ab}$ & $1.6 \mathrm{a}$ \\
\hline G19-R5-L1 & 15.4 & $17.0 \mathrm{abc}$ & $2.0 \mathrm{ab}$ & 15.0 & $15.0 \mathrm{ab}$ & $2.4 \mathrm{a}$ & $16.6 \mathrm{~b}$ & $10.0 \mathrm{c}$ & $1.1 \mathrm{~b}$ & $15.8 \mathrm{ab}$ & $14.9 \mathrm{ab}$ & $1.4 \mathrm{ab}$ \\
\hline G22-R28-F1 & 15.1 & $14.5 \mathrm{bcd}$ & $1.8 \mathrm{bc}$ & 15.0 & $15.9 \mathrm{ab}$ & $1.6 \mathrm{cde}$ & $18.2 \mathrm{ab}$ & $10.7 \mathrm{bc}$ & $1.0 \mathrm{~b}$ & $15.8 \mathrm{ab}$ & $14.1 \mathrm{ab}$ & $1.0 \mathrm{c}$ \\
\hline G34-R4-F5 & 15.2 & $12.6 \mathrm{~cd}$ & $1.8 \mathrm{bc}$ & 15.0 & $15.9 \mathrm{ab}$ & $2.1 \mathrm{abc}$ & $17.3 \mathrm{ab}$ & $10.7 \mathrm{bc}$ & $1.1 \mathrm{~b}$ & $16.4 \mathrm{ab}$ & $17.1 \mathrm{a}$ & $1.2 \mathrm{abc}$ \\
\hline Mean & $15.2 \mathrm{~A}$ & $15.5 \mathrm{~A}$ & $1.9 \mathrm{~A}$ & $15.0 \mathrm{~A}$ & $16.1 \mathrm{~A}$ & $2.0 \mathrm{~A}$ & $17.3 \mathrm{~A}$ & $11.7 \mathrm{~A}$ & $1.2 \mathrm{~A}$ & $15.9 \mathrm{~A}$ & $15.6 \mathrm{~A}$ & $1.3 \mathrm{~A}$ \\
\hline
\end{tabular}

${ }^{\mathrm{z}} \mathrm{IP}=$ incubation period, hours from inoculation to the initial symptom appearance; $\mathrm{L}=$ number of lesions per square centimeter of leaf; and $\mathrm{V}=$ virulence based on a three-scale index, where $1=<25 \%, 2=25$ to $50 \%$, and $3=>50 \%$ leaf area diseased. Means of individual isolates designated by the same lowercase letter within sensitivity groups are not significantly different according to Tukey's test $(\alpha=0.05)$. Mean values between sensitivity groups designated by the same uppercase letter are not significantly different according to Student's $t$ test $(\alpha=0.05)$. Mean values for virulence designated by the same lowercase or uppercase letter within or between sensitivity groups, respectively, are not significantly different according to Krustal-Wallis $H$ test $(\alpha=$ $0.05)$. 
production are present on this chromosome $(1,35,36)$; therefore, highly virulent isolates might have more copies of the genes controlling the toxin production than low-virulence isolates (3). In fact, a dose-response study revealed that toxin concentrations as low as $2 \times 10^{-8} \mathrm{M}$ caused brown veinal necrosis with a rapid loss of electrolytes from host cells of susceptible leaves (28). The higher virulence observed in resistant isolates suggest that, in the field, where those isolates were exposed to QoIs, a possible selection of QoI-resistant isolates with high fitness (expressed as isolates with a higher number of copies of the ACT toxin production genes) could have occurred, as previously reported (53).

Correlation analysis is one of the most powerful tools used to estimate fitness cost associated with fungicide resistance. In a previ- ous study (42), the cross resistance to five DMIs in Pyrenophora teres isolates was estimated using component correlation analyses, which involves the use of ANOVA and analysis of covariance by partitioning variation and covariation into different categories. It was found that correlation coefficients calculated with component correlation were similar to those generated by the Pearson correlation coefficient, which involves the mean of fungicide resistance phenotype, expressed as an $\mathrm{EC}_{50}$ value or growth inhibition response, and the mean of fitness components (43). Therefore, in the present study, we estimated the correlations between phenotypic sensitivities to QoI fungicides and mean fitness components by calculating Pearson correlation coefficients. This approach was previously used successfully to estimate the correlation between
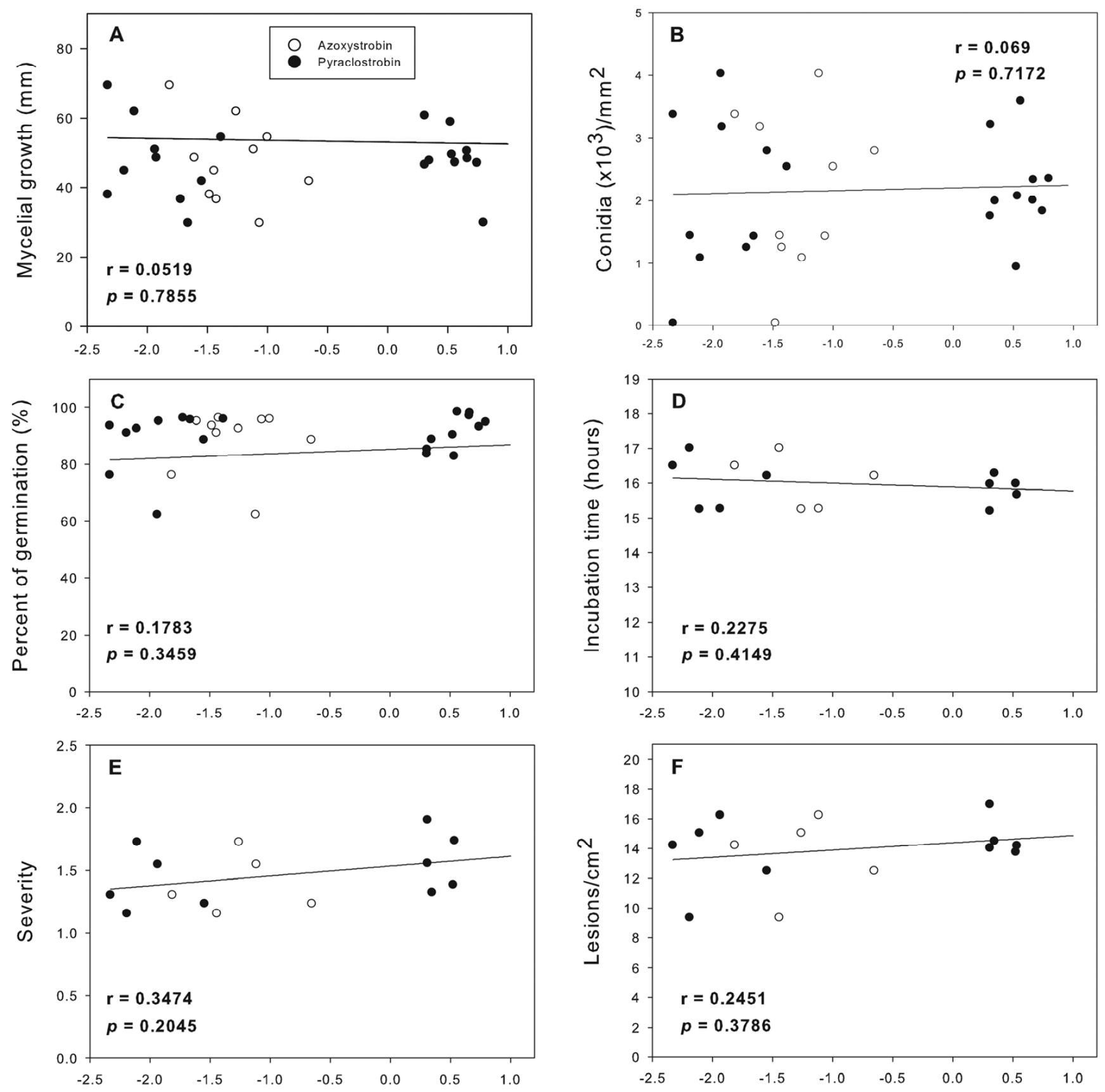

\section{$\log _{10} \mathrm{EC}_{50}(\mu \mathrm{g} / \mathrm{ml})$}

Fig. 1. A, Correlation between the level of sensitivity to azoxystrobin and pyraclostrobin and mycelial growth, B, conidial production, C, conidial germination of Alternaria alternata isolates, $\mathbf{D}$, incubation time, $\mathbf{E}$, disease severity, and $\mathbf{F}$, number of lesions caused by $A$. alternata isolates. 
fitness components and resistance to DMIs (23), anilinopyrimidines (APs) (6), succinate dehydrogenase inhibitors, and QoIs (26). Our study showed no evidence of fitness costs associated with resistance to azoxystrobin and pyraclostrobin. Moreover, the correlation coefficient values between sensitivity to QoIs and any saprophytic or pathogenic fitness components showed no significant correlation. The absence of fitness cost associated with QoI resistance in the tangerine-infecting A. alternata populations could explain the rapid emergence of QoI resistance in the field. Regardless of the stability and competitive ability of QoI-resistant isolates, permanent monitoring programs to determine the sensitivity of populations are required to track any changes in the resistance frequency around the state.

To evaluate the protective effect of azoxystrobin against QoIsensitive and -resistant isolates, immature leaves of young citrus trees were inoculated 1 day after the fungicide application. As expected, Abound was only able to control ABS caused by sensitive isolates showing that, under optimal conditions for disease development, QoI fungicides were not effective for control of ABS caused by resistant isolates. QoI resistance associated with the G143A mutation may cause complete control failure in a relatively short period of time (18), especially when the resistant isolates dominate the population. In the case of tangerine-infecting $A$. alternata, growers have observed QoI control failure when the proportion of resistance in the population exceeded $60 \%$ (56). The lack of disease control caused by resistant isolates was also reported in other pathosystems where qualitative resistance was detected using different fungicide groups. With the Alternaria sp. that infects pistachio, boscalid failed to control disease caused by resistant isolates (4). Similarly, the AP cyprodinil was only effective in controlling gray mold of strawberry caused by sensitive isolates of $B$. cinerea (15). In barley plants treated with carboxin, the percent infection was significantly higher in plants inoculated with resistant isolates of $U$. nuda than in plants inoculated with sensitive isolates (37).

The evidence presented in this study about the stability of QoIresistant A. alternata isolates from tangerine, the higher aggressiveness of resistant isolates, as well as the lack of fitness costs associated with resistance has important implications for disease management. Some strategies such as the rotation of fungicides with different modes of action, the management of application doses, or the use of fungicide mixtures have been proposed to prevent or delay the problems associated with fungicide resistance

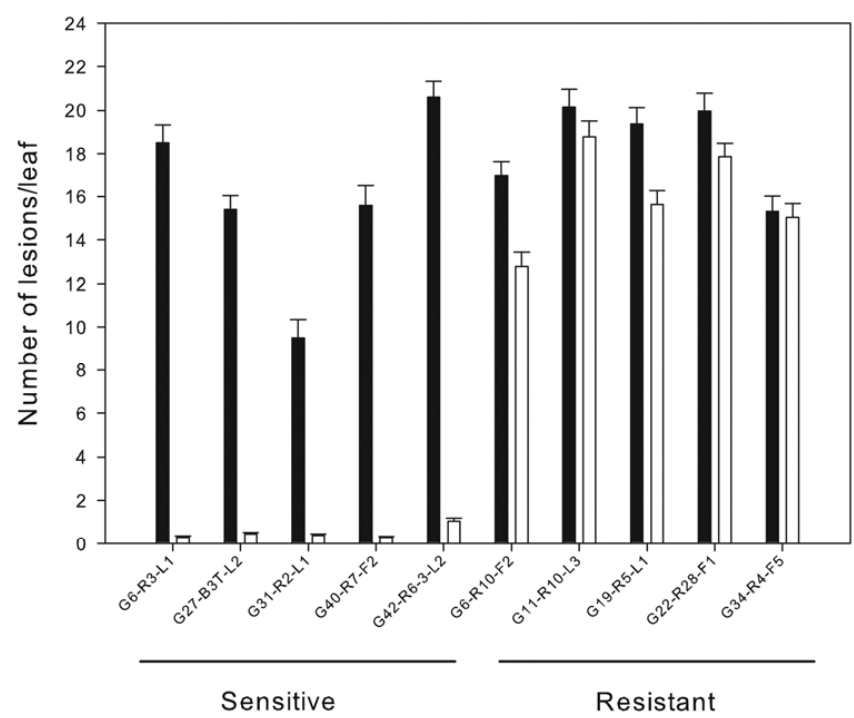

Fig. 2. Effect of azoxystrobin on control of Alternaria brown spot in 'Murcott' trees inoculated with quinone-outside inhibitor-resistant and -sensitive isolates of Alternaria alternata. Black bars represent the nontreated water control whereas white bars represent azoxystrobin-based (Abound) treatment. Vertical bars are the mean and error bars are the standard error of the number of lesions per leaf.
$(44,55)$. Due to the widespread and high frequency of QoI resistance in tangerine-infecting Alternaria populations in Florida, the use of QoIs in mixtures and in rotation with protectant fungicides such as copper and ferbam could reduce the selection of the resistant alleles. Recently, new fungicides (difenoconazole and boscalid) in mixtures with QoIs were registered and should be incorporated to disease management programs. However, studies of baseline sensitivities for those new active ingredients are necessary to monitor resistance development. Finally, further research is required to investigate the competitive ability of resistant isolates mixed in different proportions with sensitive isolates under experimental conditions.

\section{Acknowledgments}

This research was supported by the Citrus Research and Development Foundation grant number 519. We thank L. W. Timmer for critically reading this manuscript; and K. Nicoletta, P. Vega, and J. Lybbert for their technical assistance.

\section{Literature Cited}

1. Ajiro, N., Miyamoto, Y., Masunaka, A., Tsuge, T., Yamamoto, M., Ohtani, K., Fukumoto, T., Gomi, K., Peever, T. L., Izumi, Y., Tada, Y., and Akimitsu, K. 2010. Role of the host-selective ACT-toxin synthesis gene ACTTS2 encoding an enoyl-reductase in pathogenicity of the tangerine pathotype of $\mathrm{Al}$ ternaria alternata. Phytopathology 100:120-126.

2. Akamatsu, H., Taga, M., Kodama, M., Johnson, R., Otani, H., and Kohmoto, K. 1999. Molecular karyotypes for Alternaria plant pathogens known to produce host-specific toxins. Curr. Genet. 35:647-656.

3. Akimitsu, K. A., Peever, T. L., and Timmer, L. W. 2003. Molecular, ecological and evolutionary approaches to understanding Alternaria diseases of citrus. Mol. Plant Pathol. 4:435-446.

4. Avenot, H. F., and Michailides, T. J. 2007. Resistance to boscalid fungicide in Alternaria alternata isolates from pistachio in California. Plant Dis. 91:1345-1350.

5. Avila-Adame, C., and Köller, W. 2003. Characterization of spontaneous mutants of Magnaporthe grisea expressing stable resistance to the Qo-inhibiting fungicide azoxystrobin. Curr. Genet. 42:332-338.

6. Bardas, G. A., Myresiotis, C. K., and Karaoglanidis, G. S. 2008. Stability and fitness of anilinopyrimidine-resistant strains of Botrytis cinerea. Phytopathology 98:443-450.

7. Bartlett, D. W., Clough, J. M., Godwin, J. R., Hall, A. A., Hamer, M., and Parr-Dobrzanski, B. 2002. The strobilurin fungicides. Pest Manage. Sci. 58:649-662.

8. Brent, K. J., and Hollomon, D. W. 2007. Fungicide Resistance: The Assessment of Risk. FRAC Monogr. No. 2, second ed. Croplife International, Brussels.

9. Canihos, Y., Peever, T. L., and Timmer, L. W. 1999. Temperature, leaf wetness, and isolate effects on infection of Minneola tangelo leaves by Alternaria sp. Plant Dis. 83:429-433.

10. Chapara, V., Taylor, R. J., Pasche, J. S., and Gudmestad, N. C. 2011. Competitive parasitic fitness of mefenoxam-sensitive and -resistant isolates of Phytophthora erythroseptica under fungicide selection pressure. Plant Dis. 95:691-696.

11. Chen, C., Wang, J., Luo, Q., Yuan, S., and Zhou, M. 2007. Characterization and fitness of carbendazim-resistant strains of Fusarium graminearum (wheat scab). Pest Manage. Sci. 63:1201-1207.

12. Chin, K. M., Chavaillaz, D., Kaesbohrer, M., Staub, T., and Felsenstein, F. G. 2001. Characterizing resistance risk of Erysiphe graminis f. sp. tritici to strobilurins. Crop Prot. 20:87-96.

13. Cox, K., Bryson, P., and Schnabel, G. 2007. Instability of propiconazole resistance and fitness in Monilinia fructicola. Phytopathology 97:448-453.

14. Cuenca, J., Aleza, P., Vicent, A., Brunel, D., Ollitrault, P., and Navarro, L. 2013. Genetically based location from triploid populations and gene ontology of a 3.3-Mb genome region linked to Alternaria brown spot resistance in citrus reveal clusters of resistance genes. PLoS One 8:e76755.doi:10.1371/journal.pone.0076755

15. Fernández-Ortuño, D., Chen, F., and Schnabel, G. 2013. Resistance to cyprodinil and lack of fludioxonil resistance in Botrytis cinerea isolates from strawberry in North and South Carolina. Plant Dis. 97:81-85.

16. Fernández-Ortuño, D., Tores, J. A., de Vicente, A., and Pérez-García, A. 2008. Mechanisms of resistance to QoI fungicides in phytopathogenic fungi. Int. Microbiol. 11:1-9.

17. Fisher, N., Brown, A. C., Sexton, G., Cook, A., Windass, J., and Meunier, B. 2004. Modeling the Qo site of crop pathogens in Saccharomyces cerevisiae cytochrome $b$. Eur. J. Biochem. 271:2264-2271.

18. Fisher, N., and Meunier, B. 2008. Molecular basis of resistance to cytochrome $b c_{l}$ inhibitors. FEMS Yeast Res. 8:183-192.

19. Fungicide Resistance Action Committee (FRAC). 2013. List of plant pathogenic organisms resistant to disease control agents. Online publication. http://www.frac.info

20. Genet, J.-L., Jaworska, G., and Deparis, F. 2006. Effect of dose rate and 
mixtures of fungicides on selection for QoI resistance in populations of Plasmopara viticola. Pest Manage. Sci. 62:188-194.

21. Hatta, R., Ito, K., Hosaki, Y., Tanaka, T., Tanaka, A., Yamamoto, M., Akimitsu, K., and Tsuge, T. 2002. A conditionally dispensable chromosome controls host-specific pathogenicity in the fungal plant pathogen Alternaria alternata. Genetics 161:59-70.

22. Ishii, H., Yano, K., Date, H., Furuta, A., Sagehashi, Y., Yamaguchi, T., Sugiyama, T., Nishimura, K., and Hasama, W. 2007. Molecular characterization and diagnosis of QoI resistance in cucumber and eggplant fungal pathogens. Phytopathology 97:1458-1466.

23. Karaoglanidis, G., Thanassoulopoulos, C., and Ioannidis, P. 2001. Fitness of Cercospora beticola field isolates resistant and sensitive to demethylation inhibitor fungicides. Eur. J. Plant Pathol. 107:337-347.

24. Karaoglanidis, G. S., Luo, Y., and Michailides, T. J. 2011. Competitive ability and fitness of Alternaria alternata isolates resistant to QoI fungicides. Plant Dis. 95:178-182.

25. Karaoglanidis, G. S., and Thanassoulopoulos, C. C. 2002. Phenotypic instability of Cercospora beticola Sacc. strains expressing resistance to the sterol demethylation-inhibiting (DMI) fungicide flutriafol after cold exposure. J. Phytopathol. 150:692-696.

26. Kim, Y. K., and Xiao, C. L. 2011. Stability and fitness of pyraclostrobinand boscalid-resistant phenotypes in field isolates of Botrytis cinerea from apple. Phytopathology 101:1385-1391.

27. Kohmoto, K., Akimitsu, K., and Otani, H. 1991. Correlation of resistance and susceptibility of citrus to Alternaria alternata with sensitivity to hostspecific toxins. Phytopathology 81:719-722.

28. Kohmoto, K., Itoh, Y., Shimomura, N., Kondoh, Y., Otani, H., Kodama, M., Nishimura, S., and Nakatsuka, S. 1993. Isolation and biological activities of two host-specific toxins from the tangerine pathotype of Alternaria alternata. Phytopathology 83:495-502.

29. Kohmoto, K., Scheffer, R. P., and Whiteside, J. O. 1979. Host-selective toxins from Alternaria citri. Phytopathology 69:667-671.

30. Köller, W., Smith, F. D., and Reynolds, K. L. 1991. Phenotypic instability of flusilazole sensitivity in Venturia inaequalis. Plant Pathol. 40:608-611.

31. Malandrakis, A., Markoglou, A., Nikou, D., Vontas, J., and Ziogas, B. 2006. Biological and molecular characterization of laboratory mutants of Cercospora beticola resistant to Qo inhibitors. Eur. J. Plant Pathol. 116:155-166.

32. Markoglou, A., Malandrakis, A., Vitoratos, A., and Ziogas, B. 2006. Characterization of laboratory mutants of Botrytis cinerea resistant to QoI fungicides. Eur. J. Plant Pathol. 115:149-162.

33. Masunaka, A., Tanaka, A., Tsuge, T., Peever, T. L., Timmer, L. W., Yamamoto, M., Yamamoto, H., and Akimitsu, K. 2000. Distribution and characterization of AKT homologs in the tangerine pathotype of Alternaria alternata. Phytopathology 90:762-768.

34. Miguez, M., Reeve, C., Wood, P. M., and Hollomon, D. W. 2004. Alternative oxidase reduces the sensitivity of Mycosphaerella graminicola to QoI fungicides. Pest Manage. Sci. 60:3-7.

35. Miyamoto, Y., Ishii, Y., Honda, A., Masunaka, A., Tsuge, T., Yamamoto, M., Ohtani, K., Fukumoto, T., Gomi, K., Peever, T. L., and Akimitsu, K. 2009. Function of genes encoding acyl-CoA synthetase and enoyl-CoA hydratase for host-selective ACT-toxin biosynthesis in the tangerine pathotype of Alternaria alternata. Phytopathology 99:369-377.

36. Miyamoto, Y., Masunaka, A., Tsuge, T., Yamamoto, M., Ohtani, K., Fukumoto, T., Gomi, K., Peever, T. L., and Akimitsu, K. 2008. Functional analysis of a multicopy host-selective ACT-toxin biosynthesis gene in the tangerine pathotype of Alternaria alternata using RNA silencing. Mol. PlantMicrobe Interact. 21:1591-1599.

37. Newcombe, G., and Thomas, P. L. 2000. Inheritance of carboxin resistance in a European field isolate of Ustilago nuda. Phytopathology 90:179-182.

38. Otani, H., Kohmoto, K., and Kodama, M. 1995. Alternaria toxins and their effects on host plants. Can. J. Bot. 73:S453-S458.

39. Pasche, J. S., and Gudmestad, N. C. 2008. Prevalence, competitive fitness and impact of the F129L mutation in Alternaria solani from the United States. Crop Prot. 27:427-435.
40. Peever, T. L., Canihos, Y., Olsen, L., Ibanez, A., Liu, Y. C., and Timmer, L. W. 1999. Population genetic structure and host specificity of Alternaria spp. causing brown spot of Minneola tangelo and rough lemon in Florida. Phytopathology 89:851-860.

41. Peever, T. L., Ibañez, A., Akimitsu, K., and Timmer, L. W. 2002. Worldwide phylogeography of the citrus brown spot pathogen, Alternaria alternata. Phytopathology 92:794-802.

42. Peever, T. L., and Milgroom, M. G. 1993. Genetic correlations in resistance to sterol biosynthesis-inhibiting fungicides in Pyrenophora teres. Phytopathology 83:1076-1082.

43. Peever, T. L., and Milgroom, M. G. 1994. Lack of correlation between fitness and resistance to sterol biosynthesis-inhibiting fungicides in Pyrenosphora teres. Phytopathology 84:515-519.

44. Peever, T. L., and Milgroom, M. G. 1995. Fungicide resistance: Lessons for herbicide resistance management? Weed Technol. 9:840-849.

45. Peever, T. L., Su, G., Carpenter-Boggs, L., and Timmer, L. W. 2004. Molecular systematics of citrus-associated Alternaria species. Mycologia 96:119 134.

46. Penrose, L., Davis, K., and Koffmann, W. 1979. The distribution of benomyl-tolerant Sclerotinia fructicola (Wint.) Rehm. in stone fruit orchards in New South Wales and comparative studies with susceptible isolates. Aust. J Agric. Res. 30:307-319.

47. Pringle, A., and Taylor, J. W. 2002. The fitness of filamentous fungi. Trends Microbiol. 10:474-481.

48. Raposo, R., Gomez, V., Urrutia, T., and Melgarejo, P. 2000. Fitness of Botrytis cinerea associated with dicarboximide resistance. Phytopathology 90:1246-1249.

49. Ritchie, D. 1983. Mycelial growth, peach fruit-rotting capability, and sporulation of strains of Monilinia fructicola resistant to dichloran, iprodione, procymidone, and vinclozolin. Phytopathology 73:44-47.

50. Schüepp, H., and Küng, M. 1981. Stability of tolerance to MBC in populations of Botrytis cinerea in vineyards of northern and eastern Switzerland. Can. J. Plant Pathol. 3:180-181.

51. Stewart, J. E., Thomas, K. A., Lawrence, C. B., Dang, H., Pryor, B. M. Timmer, L. M., and Peever, T. L. 2013. Signatures of recombination in clonal lineages of the citrus brown spot pathogen, Alternaria alternata sensu lato. Phytopathology 103:741-749.

52. Tsuge, T., Harimoto, Y., Akimitsu, K., Ohtani, K., Kodama, M., Akagi, Y. Egusa, M., Yamamoto, M., and Otani, H. 2013. Host-selective toxins produced by the plant pathogenic fungus Alternaria alternata. FEMS Microbiol. Rev. 37:44-66.

53. Uyenoyama, M. K. 1986. Pleiotropy and the evolution of genetic systems conferring resistance to pesticides. Pages 207-221 in: Pesticide Resistance: Strategies and Tactics for Management. National Research Council, Committee on Strategies for the Management of Pesticide Resistant Pest Populations, eds. National Academy Press, Washington, DC.

54. van den Bosch, F., and Gilligan, C. A. 2008. Models of fungicide resistance dynamics. Annu. Rev. Phytopathol. 46:123-147.

55. van den Bosch, F., Paveley, N., Shaw, M., Hobbelen, P., and Oliver, R. 2011. The dose rate debate: Does the risk of fungicide resistance increase or decrease with dose? Plant Pathol. 60:597-606.

56. Vega, B., and Dewdney, M. M. 2014. Distribution of QoI resistance in populations of tangerine-infecting Alternaria alternata in Florida. Plant Dis. 98:67-76.

57. Vega, B., Liberti, D., Harmon, P. F., and Dewdney, M. M. 2012. A rapid resazurin-based microtiter assay to evaluate QoI sensitivity for Alternaria alternata isolates and their molecular characterization. Plant Dis. 96:12621270

58. Zheng, D., Olaya, G., and Köller, W. 2000. Characterization of laboratory mutants of Venturia inaequalis resistant to the strobilurin-related fungicide kresoxim-methyl. Curr. Genet. 38:148-155.

59. Ziogas, B. N., Markoglou, A. N., and Tzima, A. 2002. A non-Mendelian inheritance of resistance to strobilurin fungicides in Ustilago maydis. Pest Manage. Sci. 58:908-916. 